\title{
Case Report and Review of the Literature of Schwannomas That Originate from Falx Cerebri
}

Kosuke Nakajo, Takehiro Uda, Tsuyoshi Sasaki, Sayaka Tanaka, Shugo Nishijima, Yusuke Watanabe, Kazuhiro Yamanaka, Kenji Ohata

\begin{tabular}{|c|l|}
\hline Citation & World Neurosurgery, 124; $52-55$ \\
\hline Issue Date & $2019-04$ \\
\hline Type & Journal Article \\
\hline Textversion & Author \\
\hline \multirow{3}{*}{ Rights } & $\begin{array}{l}\text { C } 2019 \text { Elsevier Inc. This manuscript version is made available under the } \\
\text { CC-BY-NC-ND 4.0 License. http://creativecommons.org/licenses/by-nc-nd/4.0/. } \\
\text { This is the accepted manuscript version. The article has been published in final form } \\
\text { at https://doi.org/10.1016/j.wneu.2018.12.122. }\end{array}$ \\
\hline DOI & $10.1016 /$ j.wneu.2018.12.122 \\
\hline
\end{tabular}

\section{Self-Archiving by Author(s)}

Placed on: Osaka City University Repository 
Case Report and Review of the Literature of Schwannomas that Originate from the Falx Cerebri

Kosuke NAKAJO ${ }^{1}$, Takehiro UDA ${ }^{1}$, Tsuyoshi SASAKI ${ }^{1}$, Sayaka TANAKA ${ }^{2}$, Shugo NISHIJIMA ${ }^{1}$, Yusuke WATANABE ${ }^{1}$, Kazuhiro YAMANAKA $^{1}$, Kenji OHATA $^{1}$

The Departments of ${ }^{1}$ Neurosurgery and ${ }^{2}$ Pathology, Osaka City University Graduate School of Medicine, Osaka, Japan

Key words: falx cerebri, schwannoma 
Abbreviations and Acronyms:

CT: Computed tomography, MRI: Magnetic resonance imaging, Met-PET:

${ }^{11} \mathrm{C}$-Methionine positron emission tomography, SSS: Superior sagittal sinus,

Correspondence to:

Kosuke Nakajo, MD

Department of Neurosurgery, Osaka City University Graduate School of Medicine 1-4-3 Asahi-machi, Abeno-ku, Osaka 545-8585, Japan

Tel: +81-6-6645-3846; Fax: +81-6-6647-8065

E-mail: kousuke19841984@yahoo.co.jp 


\begin{abstract}
BACKGROUND: Schwannomas not related to cranial nerves are very rare. Here, we present a case of a schwannoma that originated from the falx cerebri and review reported cases in the literature.

CASE DESCRIPTION: A 36-year-old male experienced generalized seizures following right hemiparesis predominantly in his lower extremity. Magnetic resonance imaging revealed a round tumor attached to the falx cerebri on the left side. Radiologically, the tumor appeared to be a falx meningioma. We performed gross total removal of the tumor. Pathology showed a schwannoma that originated from the falx cerebri. Right hemiparesis disappeared soon after surgery.

CONCLUSION: Although distinguishing a schwannoma of the falx cerebri from a falx meningioma and metastasis is difficult preoperatively, inclusion of schwannoma of the falx cerebri in the differential diagnosis is important, especially when the patient is relatively young and/or the tumor lacks dural tail sign.
\end{abstract}




\section{Highlights}

- Schwannomas not related to cranial nerves are extremely rare.

- We present a case of schwannoma that originated from the falx cerebri.

- It is difficult to distinguish a falx schwannoma from a falx meningioma.

- Young patient and/or lack of dural tail sign might support the preoperative diagnosis of falx schwannoma. 


\section{Introduction}

Intracranial schwannomas constitute about $8 \%$ of all intracranial tumors. ${ }^{1-7}$ Most schwannomas originate from cranial nerves such as the vestibular nerve, trigeminal nerve, facial nerve, vagus nerve, or glossopharyngeal nerve and are located in the cerebellopontine cistern or middle fossa around these nerves. Schwannomas not located around these nerves are rare. In such cases, tumors are often misdiagnosed as meningiomas, gliomas or metastases. Here, we report an extremely rare case of a schwannoma that originated from the falx cerebri and review previous reports.

\section{Case Report}

A 36-year-old male presented with generalized seizures. Neurological examination showed right hemiparesis predominantly in his lower limb. He did not have a medical history, family history, or any sign of neurofibromatosis. Magnetic resonance imaging (MRI) revealed a round tumor along the middle third of the falx cerebri on the left side. The tumor showed slight hypo- to iso-intensity on T1-weighted images and iso- to slightly high intensity on T2-weighted images compared with the brain parenchyma and was accompanied by peritumoral edema (Figure 1a, b). The tumor was enhanced heterogeneously with gadolinium and did not have an apparent dural tail sign (Figure 1c, d). Susceptibility-weighted imaging suggested an intratumoral hemorrhage (Figure 1e). A heavily $\mathrm{T} 2$-weighted image revealed that some parts of the tumor did not have a clear margin between the tumor and brain parenchyma (Figure 1f). The tumor showed slightly high density and no calcification on computed tomography (CT). We also observed a peritumoral low-density area (Figure 1g). Bone density CT showed no hyperostosis or erosion of the surrounding skull. From these imaging findings, we 
initially diagnosed the tumor as a falx meningioma with intratumoral hemorrhage, but could not exclude the possibility of intraaxial tumors such as epithelioid glioblastoma or metastasis. Tumor marker such as squamous cell carcinoma antigen, carcinoembryonic antigen, carbohydrate antigen 19-9, prostate specific antigen and soluble interleukin-2 receptor were negative. Torso CT revealed no apparent malignant tumor.

${ }^{11} \mathrm{C}$-Methionine positron emission tomography (Met-PET) showed high accumulation of the tracer (mean tumor to normal cerebellum ratio: 3.26) (Figure 1h). We performed surgery via an ipsilateral interhemispheric approach. Intraoperative findings showed that the tumor was completely located extraaxially and was attached to the falx cerebri without invasion into the superior sagittal sinus (SSS). We achieved gross total resection including the falx cerebri. Histological analysis showed interlacing fascicles of spindle cells that were devoid of Verocay bodies (Figure 2a). Tumor cells were reactive for S-100 protein and negative for glial fibrillary acidic protein and CD34 (Figure 2b, c). Epithelial membrane antigen reactivity was cytoplasmic (Figure 2d). The final diagnosis was a schwannoma. The MIB-1 labeling index was 4.2\% (Figure 2e). Postoperative MRI showed no apparent residual tumor (Figure 3). His right hemiparesis had disappeared when he was discharged from the hospital and no seizure has occurred during the six months after surgery.

\section{Discussion}

Schwannomas not related to the cranial nerves are rare. Up to now, approximately 70 cases have been reported. ${ }^{1}$ In particular, to the best of our knowledge, schwannomas that originated from the falx cerebri and/or SSS are extremely rare, with only nine reported cases (Table 1). ${ }^{1-6,8,9}$ 


\section{Features of schwannomas of the falx cerebri and/or SSS}

In the nine previously reported cases regarded as an intracranial schwannoma attached to the falx cerebri and/or SSS, ${ }^{1-6,8,9}$ four cases were schwannomas that originated from the falx cerebri, ${ }^{5,6,8,9}$ three cases were parasagittal schwannomas, ${ }^{1,2,4}$ and two cases were schwannomas that were attached to both the falx cerebri and SSS. ${ }^{3,6}$ Bruni et al. reported a case of a parasagittal schwannoma that was related to neurofibromatosis; ${ }^{2}$ the other eight cases were not related to neurofibromatosis. The patients with intracranial schwannomas that originated from the falx cerebri and/or SSS were relatively young (ranging from 12-70 years; mean age 29.2 years) and showed a slight male predominance (male:female $=5: 3$; the sex of one patient was unknown), although some authors reported no gender predominance. Around $70 \%$ of patients were younger than 30 years old. ${ }^{10}$ Common symptoms were seizures and motor weakness. Russel and Robinstein reported a case of a schwannoma attached to the falx cerebri in a 12-year-old boy. His tumor showed diffuse local brain invasion as well as osseous metastasis. ${ }^{6}$ Vaquero et al. reported multiple solid schwannomas arising from the falx cerebri that showed homogeneous enhancement after administration of contrast material. Because this patient had undergone a previous operation for an intraparenchymal schwannoma, they referred to the possibility of a seeding metastasis. ${ }^{8}$ In the previous reports, the MRI features were described in three cases. ${ }^{1,3,5}$ Among these three cases, two cases did not have an apparent dural tail sign, as also seen in our present case. Zagardo et al. reported that intracranial schwannomas tend to show cyst formation, calcification, peritumoral edema, and gliosis. ${ }^{10}$ However, among patients with intracranial schwannomas that originated from the falx cerebri and/or SSS, only three patients had a cystic component. ${ }^{3,5,9}$ Also, in the present case, imaging findings 
revealed peritumoral edema but no apparent cyst formation or calcification. The edema seemed to be caused by compression of the surrounding cortical vein. Our patient showed peritumoral edema that rapidly increased in size, suggesting that this tumor was an extramedullary tumor such as meningioma, schwannoma or metastasis. We could not exclude the possibility of intramedullary tumors preoperatively.

Nyberg et al. evaluated the uptake of methionine in schwannomas and meningiomas that were located around the skull base. They concluded that skull base schwannomas show a lower tumor to cerebellum ratio of methionine accumulation (tumor to cerebellum ratio ranges from 1.1-1.87, mean 1.48) than skull base meningiomas (tumor to cerebellum ratio ranges from 2.62-5.37, mean 3.63). ${ }^{11}$ Sakamoto et al. evaluated acoustic neurinomas with Met-PET. They reported that the tumor to normal gray matter ratio was $1.694 \pm 0.266($ mean $\pm \mathrm{SD}){ }^{12}$

In the present case, the mean tumor to normal cerebellum ratio was 3.26, which was higher compared with previous reports. Met-PET may not be useful for distinguishing schwannomas of the falx cerebri from other tumors.

Regardless of the tumor pathology, the most adequate therapeutic strategy to relief the patient from the symptoms is resecting the tumor. If the tumors proved to be a metastasis, we should consider an adjuvant therapy including radiotherapy and/or chemotherapy.

\section{Origin of schwannomas of the falx cerebri}

Although controversy remains about the origin of schwannomas that are not related to cranial nerves, some hypotheses have been proposed. ${ }^{2,3,6,7,9}$ Theories about congenital abnormalities have been suggested. During embryonic development, some multipotential mesenchymal cells or misplaced neural crest cells may be the origin of 
ectopic schwann cells. ${ }^{6}$ Another theory that suggests a congenital abnormality is that intracerebral schwann cells originate from pial cells of the meninges. ${ }^{2,6}$ On the other hand, theories about acquired abnormalities have also been suggested. The first division of the trigeminal nerve is found near the falx cerebri, dura mater, and tentorium cerebelli, where it may cause a schwannoma along the falx cerebri. ${ }^{7,9}$ Another theory for an acquired abnormality suggests that the tumor origin is schwann cells around arteries in the perivascular nerve plexus. ${ }^{3}$ In the present case, the former hypothesis of an acquired origin seems the most plausible because the tumor invaded the falx cerebri.

\section{Conclusion}

We report an extremely rare case of an intracranial schwannoma that originated from the falx cerebri. Preoperatively, distinguishing a schwannoma of the falx cerebri from other intracranial tumors such as a falx meningioma or metastasis was difficult. The initial therapeutic strategy was a surgical resection regardless of the histology of the tumors. However, including schwannoma in the differential diagnosis of a tumor that originates from the falx cerebri is important, especially when the patient is relatively young and/or the tumor lacks dural tail sign. 


\section{Conflicts of interest}

No funds were received in support of this work. No benefits in any form have been or will be received from a commercial party related directly or indirectly to the subject of this manuscript. 


\section{References}

1. Raswan US, Bhat I, Samoon N, Arif SH, Laharwal M, Chhiber SS, et al. Supratentorial extraparenchymal schwannoma mimicking parasagittal meningioma: A rare case report. Surg Neurol Int. 2017;8:228.

2. Bruni P, Esposito S, Greco R, Oddi G. Solitary intracerebral schwannoma in von Recklinghausen's disease. Surg Neurol. 1984;22:360-364.

3. Ma L, Yang SX, Wang YR. Intracerebral schwannoma mimicking parasagittal meningioma. $J$ Craniofac Surg. 2013;24:e541-543.

4. Ghosh S, Chandy MJ. Solitary ectopic intracerebral schwannoma. Br J Neurosurg. 1992;6:163-166.

5. Celikoglu E, Hakan T, Bozbuga M. Cystic schwannoma of the falx cerebri. J Clin Neurosci. 2007;14:589-592.

6. Russels DS, Rubinstein LJ. Pathology of tumors of the nervous system. 5th ed. London: Edward Arnold; 1989. pp. 776-7.

7. Nagata T, Goto T, Ichinose T, Tsuyuguchi N, Ohata K. Tentorial schwannoma mimicking meningioma. Neurol Med Chir (Tokyo). 2011;51:382-385.

8. Vaquero J, Martinez R, Coca S, Vegazo I. Schwannomas of the falx. Surg Neurol. 1990;34:160-163.

9. Horgan MA, Kernan JC, Delashaw JB, Schwartz MS, Kuether T. Schwannoma of the torcula presenting as an occipital mass. Case illustration. J Neurosurg. 1998;89:490.

10. Zagardo MT, Castellani RJ, Rees JH, Rothman MI, Zoarski GH. Radiologic and pathologic findings of intracerebral schwannoma. AJNR Am J Neuroradiol. 1998;19:1290-1293.

11. Nyberg G, Bergstrom M, Enblad P, Lilja A, Muhr C, Langstrom B. PET-methionine of skull base neuromas and meningiomas. Acta Otolaryngol. 1997;117:482-489.

12. Sakamoto H, Nakai Y, Matsuda M, Ohashi Y, Tsuyuguchi N, Kawabe J, et al. Positron emission tomographic imaging of acoustic neuromas. Acta Otolaryngol Suppl. 2000;542:18-21. 


\section{Figure legends}

Fig. 1

The tumor showed hypo-intensity on a T1-weighted image (a), iso- to high intensity on a T2-weighted image (b), and heterogeneous enhancement with gadolinium (c, d). Susceptibility-weighted imaging suggested an intratumoral hemorrhage (e). The tumor did not have an apparent dural tail sign. A heavily T2-weighted image revealed that some parts of the tumor did not have a clear margin between the tumor and brain parenchyma (f). The tumor showed slightly high density with peritumoral edema on computed tomography (g). ${ }^{11} \mathrm{C}-$ Methionine positron emission tomography showed high accumulation of the tracer (h).

Fig. 2

Interlacing fascicles of spindle cells (a). Tumor cells were reactive for S-100 protein (b) and negative for glial fibrillary acidic protein and CD34 (c). Epithelial membrane antigen reactivity was cytoplasmic (d). a: Hematoxylin-eosin staining, $\times 100$. b: S-100, $\times 200$. c: CD34, $\times 200$. d: EMA, $\times 200$. The MIB-1 labeling index was $4.2 \%, \times 100$ (e).

Fig. 3

Postoperative contrast-enhanced MRI showed no apparent residual tumor with gadolinium (a: axial, b: sagittal, c: coronal). 
Table 1. Literature review of nine cases and our case of schwannomas attached to the falx cerebri and/or superior sagittal sinus.

\begin{tabular}{|c|c|c|c|c|c|}
\hline Series & Age/Sex & Presenting Symptoms & Imaging Features & Location & Patient status after surgery \\
\hline Bruni et al., $1984^{2}$ & 39/M & $\begin{array}{l}\text { Seizures } \\
\text { Café-au-lait spots, } \\
\text { Neurofibromas }\end{array}$ & Enhancement mass & SSS & Generalized seizures remained \\
\hline \multirow{2}{*}{$\begin{array}{l}\text { Russel and } \\
\text { Robinstein, } 1989^{6}\end{array}$} & $17 /-$ & - & - & Falx & - \\
\hline & $12 / \mathrm{M}$ & - & $\begin{array}{l}\text { Diffuse local brain invasion } \\
\text { Osseous metaplasia }\end{array}$ & Falx, SSS & - \\
\hline Vaquero et al., $1990^{8}$ & $17 / \mathrm{F}$ & Seizures & $\begin{array}{l}\text { Multiple solid masses } \\
\text { Homogeneous enhancement }\end{array}$ & Falx & No seizures at 2 years \\
\hline $\begin{array}{l}\text { Ghosh and Chandy, } \\
1992^{4}\end{array}$ & $27 / \mathrm{M}$ & $\begin{array}{l}\text { Seizures } \\
\text { Mild left hemiparesis } \\
\text { Headache }\end{array}$ & $\begin{array}{l}\text { Solid mass } \\
\text { Homogeneous enhancement }\end{array}$ & SSS & - \\
\hline Horgan et al., $1998^{9}$ & $27 / \mathrm{M}$ & Soft mass of the occiput & Solid cystic mass & Falx & - \\
\hline $\begin{array}{l}\text { Celikoglu et al., } \\
2007^{5}\end{array}$ & $23 / \mathrm{F}$ & $\begin{array}{l}\text { Seizures } \\
\text { Left hemiparesis }\end{array}$ & $\begin{array}{l}\text { Irregular shape } \\
\text { Solid cystic mass } \\
\text { Heterogeneous enhancement }\end{array}$ & Falx & $\begin{array}{l}\text { No symptoms and no recurrence at } 4 \\
\text { years }\end{array}$ \\
\hline Ma et al., $2013^{3}$ & $24 / \mathrm{F}$ & Seizures & $\begin{array}{l}\text { Solid cystic mass } \\
\text { Heterogeneous enhancement } \\
\text { Dural tail sign }\end{array}$ & Falx, SSS & $\begin{array}{l}\text { Seizure free } \\
\text { No recurrence at } 1 \text { year }\end{array}$ \\
\hline Raswan et al., $2017^{1}$ & $70 / \mathrm{M}$ & $\begin{array}{l}\text { Seizures } \\
\text { Left lower limb weakness }\end{array}$ & $\begin{array}{l}\text { Huge solid mass } \\
\text { Homogeneous enhancement } \\
\text { Midline shift }\end{array}$ & SSS & Uneventful \\
\hline Present case & $36 / \mathrm{M}$ & $\begin{array}{l}\text { Seizures } \\
\text { Right hemiparesis }\end{array}$ & Heterogeneous enhancement & Falx & Symptom free \\
\hline
\end{tabular}

M, male; F, female; SSS, superior sagittal sinus; —, information unknown. 
Figure1

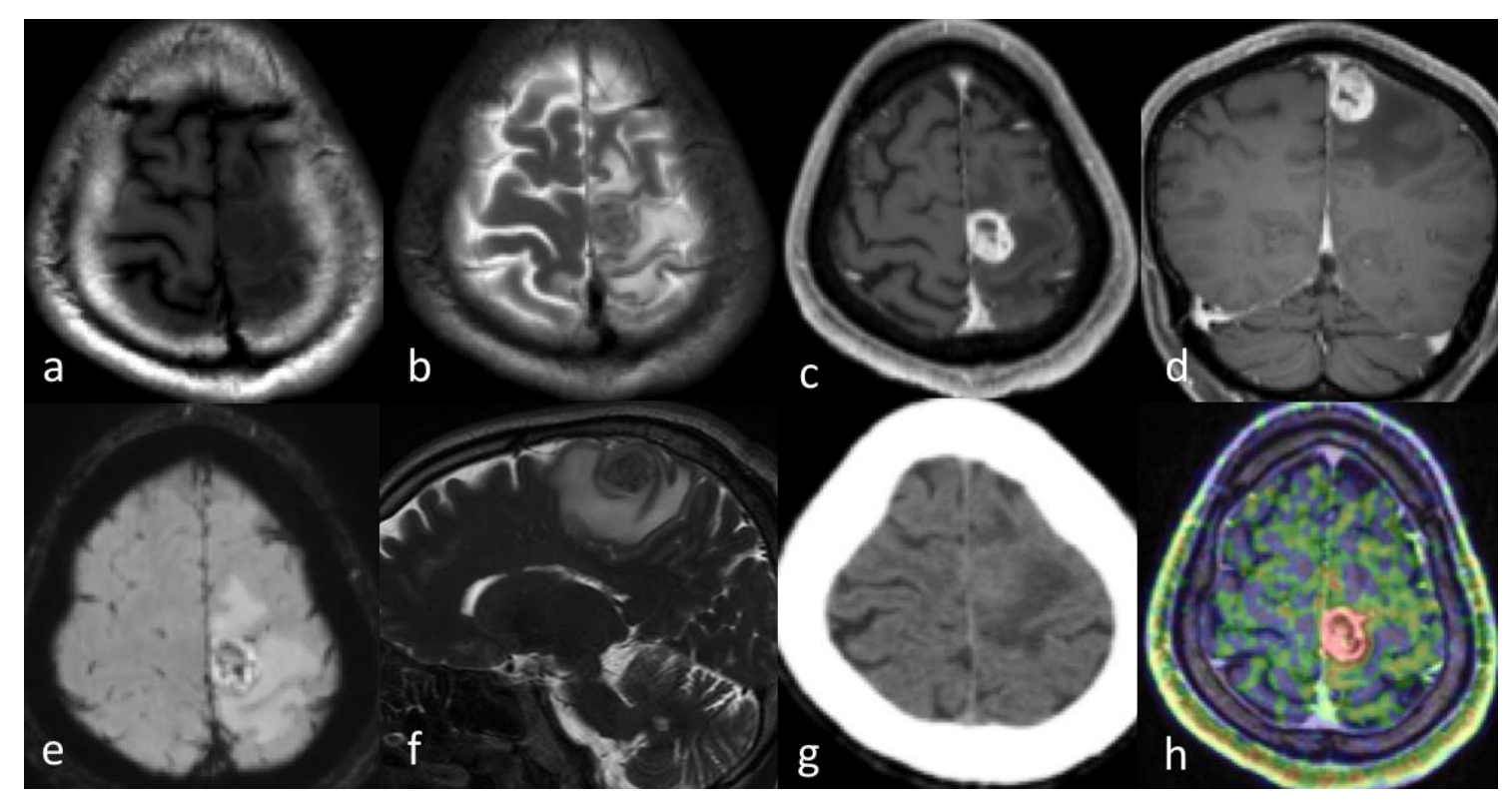

Figure2

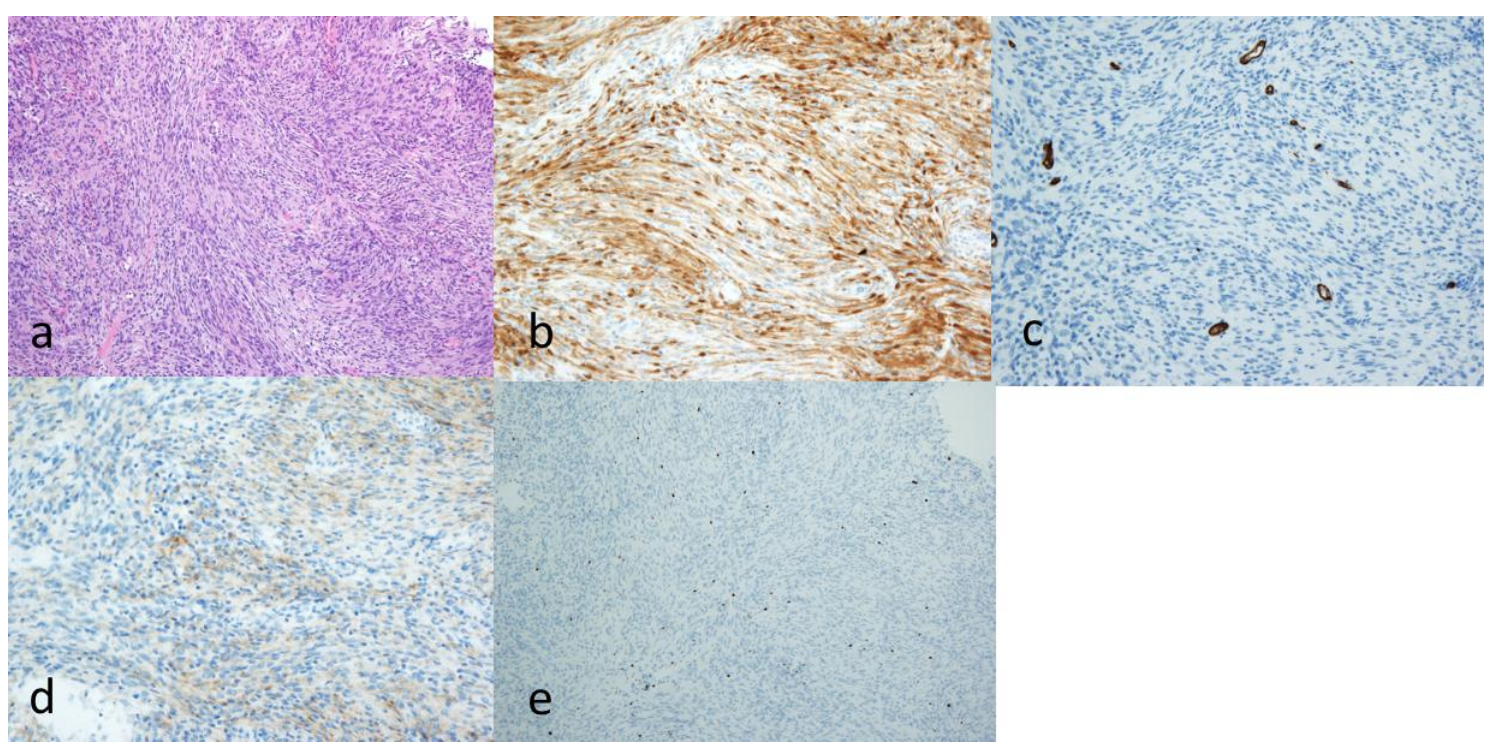


Figure3

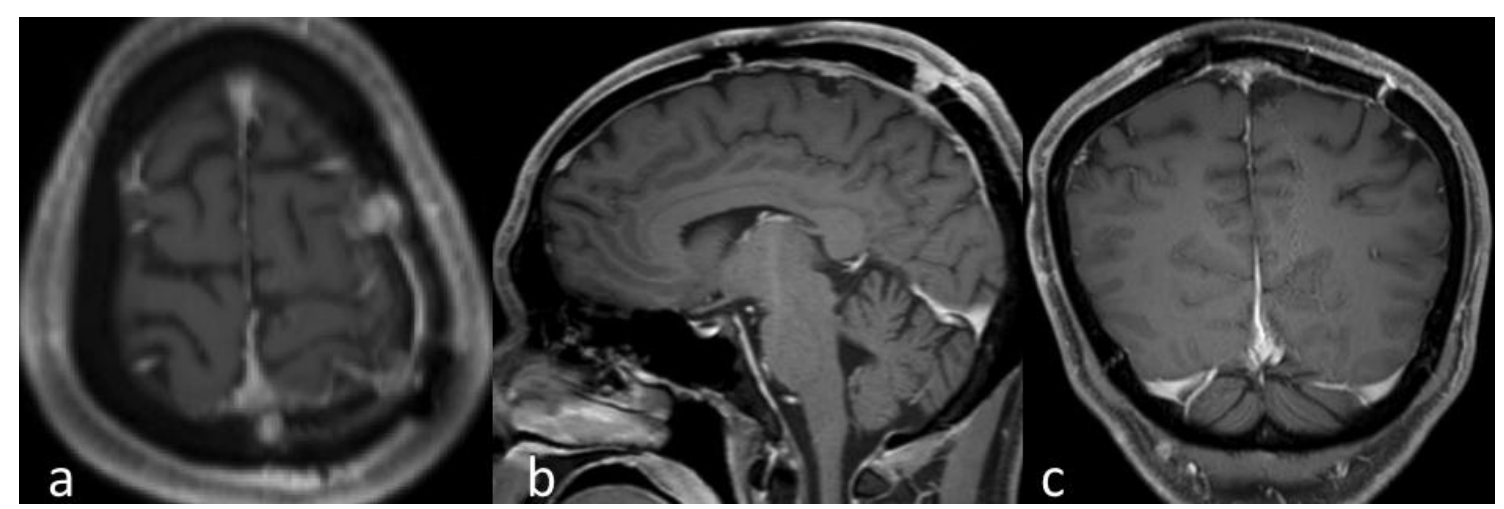

